Old Dominion University

ODU Digital Commons

CCPO Publications

Center for Coastal Physical Oceanography

6-1995

\title{
On the Interpentadal Variability of the North Atlantic Ocean: Model Simulated Changes in Transport, Meridional Heat Flux and Coastal Sea Level Between 1955-1959 and 1970-1974
}

Tal Ezer

Old Dominion University, tezer@odu.edu

George L. Mellor

Richard J. Greatbatch

Follow this and additional works at: https://digitalcommons.odu.edu/ccpo_pubs

Part of the Climate Commons, and the Oceanography Commons

\section{Repository Citation}

Ezer, Tal; Mellor, George L.; and Greatbatch, Richard J., "On the Interpentadal Variability of the North Atlantic Ocean: Model Simulated Changes in Transport, Meridional Heat Flux and Coastal Sea Level Between 1955-1959 and 1970-1974" (1995). CCPO Publications. 124.

https://digitalcommons.odu.edu/ccpo_pubs/124

\section{Original Publication Citation}

Ezer, T., Mellor, G.L., \& Greatbatch, R.J. (1995). On the interpentadal variability of the North Atlantic Ocean: Model simulated changes in transport, meridional heat flux and coastal sea level between 1955-1959 and 1970-1974. Journal of Geophysical Research: Oceans, 100(C6), 10,559-510,566. doi: 10.1029/95JC00659 


\title{
On the interpentadal variability of the North Atlantic Ocean: Model simulated changes in transport, meridional heat flux and coastal sea level between 1955-1959 ảnd 1970-1974
}

\author{
Tal Ezer and George L. Mellor \\ Program in Atmospheric and Oceanic Sciences, Princeton University, Princeton, New Jersey \\ Richard J. Greatbatch \\ Department of Physics, Memorial University of Newfoundland. St. John's. Canada
}

\begin{abstract}
Previous studies by Greatbatch et al. (1991) indicate significant changes in the North Atlantic thermohaline structure and circulation between the pentads 1955-1959 and 1970-1974, using data analyzed by Levitus $(1989 \mathrm{a}, \mathrm{b}, \mathrm{c})$ and a simple diagnostic model by Mellor et al. (1982). In this paper these changes are modeled using a three-dimensional, free surface, coastal ocean model. Diagnostic and short-term prognostic calculations are used to infer the dynamically adjusted fields corresponding to the observed hydrographic and wind stress climatology of each pentad. While the results agree with earlier studies indicating that the Gulf Stream was considerably weaker (by about $30 \mathrm{~Sv}$ ) during the 1970s compared to the 1950 s, they also indicate some changes in the poleward heat transport, although the statistical significance of these changes relative to sampling errors in the data is not clear. The change of wind pattern between the two pentads, associated with changes in sea surface temperature, resulted in changes in the Ekman contribution to the poleward heat flux transport. The modeled sea level along the North American coast shows a sea level rise of about 5-10 cm between 1955-1959 and 1970-1974; a comparison with observed sea level at 15 tide gage stations shows good agreement. Most of the coastal sea level change is attributed to changes in thermohaline ocean circulation and wind stress; thermal expansion seems to play a lesser role. The methodology tested here demonstrates an effective way to estimate climate changes in ocean circulation and sea level from observed hydrographic data and winds using ocean models to enhance and analyze the data.
\end{abstract}

\section{Introduction}

Hydrographic data such as those collected during the World Ocean Circulation Experiments (WOCE) are intended to indicate climatic changes such as those associated with an increase in greenhouse gases. Ocean models could help in the analyses of these data sets by adding dynamical constraints and the calculation of fields that are not directly observed such as thermohaline circulation and meridional heat flux. This type of calculation is done with diagnostic models [e.g., Sarmiento and Bryan, 1982; Mellor et al., 1982] or inverse optimization and assimilation [e.g., Tziperman et al., 1992; Marotzke and Wunsch, 1993].

The usefulness of combining hydrographic data with ocean model dynamics to infer climatic change is tested here using historical data from the 1950s and 1970s wherein changes in the thermohaline structure have occurred [Levitus, 1989a,b,c]. For example, between 1955-1959 and 1970-1974 the upper ocean freshened in the subarctic gyre [Levitus, 1989b], and the subtropical gyre cooled and freshened at intermediate depths resulting in substantial displacements of isopycnal

Copyright 1995 by the American Geophysical Union.

Paper number 95JC00659.

0148-0227/95/95JC-00659\$05.00 surfaces [Levitus, 1989a]. To evaluate the possible consequences of these changes, the sea level change has been estimated from steric sea level calculations [Levitus, 1990]. Changes of total transport [Greatbatch et al., 1991] and velocity fields [Isayev and Levitus, 1993, 1995] have been calculated using a diagnostic model based on that developed by Mellor et al. [1982]. The results of these analyses and the simple diagnostic calculations suggest that significant changes have occurred between the two periods: steric sea level dropped by 17.5 dynamic centimeters in the subtropical gyre, and the Gulf Stream weakened by some $30 \mathrm{~Sv}$. Some doubts about those analyses can be raised due to sampling errors in the hydrographic data used to form the climatology of each period and the assumptions used in the calculations (e.g., the steric sea level calculations must assume level of no motion; the vertically integrated vorticity balance equation used in the diagnostic model of Mellor et al. [1982] neglects advection and dissipation of momentum). Moreover, a recent diagnostic calculation by Ezer and Mellor [1994] using a three-dimensional, sigma coordinate ocean model indicates that the Levitus [1982] climatology produces noisy velocity fields and unrealistic meridional circulation due to the inconsistencies between the hydrographic data and bottom topography. On the other hand, the latter study demonstrated a simple way of dynamically adjusting the density field to topography and forcing using a short-term prognostic calculation. 
This study has two main goals. The first goal is to corroborate or challenge the previous results obtained with the simple diagnostic model by use of a nonlinear, threedimensional model and to estimate changes in the meridional overturning and meridional heat flux which previously could not be calculated. The second goal is to further compare the results against observations; in particular, sea level tide gage data are used as independent evidence that these climatic changes are real.

The paper is organized as follows: First, in section 2 the methodology and the data used are described. The spatial changes in circulation are presented and compared with previous calculations in section 3 , whereas changes in the meridional circulation and heat flux transport are discussed in sections 4. Changes in sea level are presented and compared with observations in section 5 . Finally, discussion and conclusions are offered in section 6 .

\section{Model, Data, and Methodology}

The model, its grid, and the diagnostic-prognostic methodology are the same as used by Ezer and Mellor [1994], and they will be described only briefly here. The Princeton Ocean Model (POM) [Blumberg and Mellor, 1987] is a threedimensional, free surface, ocean model with a second moment turbulence closure scheme [Mellor and Yamada, 1982] to provide vertical mixing coefficients. The vertical grid uses 15 bottom-following sigma levels. The horizontal grid uses a coastal-following, curvilinear orthogonal system with resolution of $20-30 \mathrm{~km}$ in the western Atlantic and $80-100 \mathrm{~km}$ in the eastern Atlantic. At the southern open boundary (at $10^{\circ} \mathrm{N}$ ), inflow/outflow velocities are taken from simulations with a model of the entire Atlantic Ocean and are fixed for all experiments. At the northern open boundary around $65^{\circ} \mathrm{N}$ the vertically integrated velocity perpendicular to the boundary is zero, but the velocity at each level is free to adjust geostrophically to the density field, using a radiation condition. On all open boundaries the temperature and salinity fields used as initial condition for each experiment are also used as boundary condition, where such temperatures and salinities are advected into the model domain under inflow conditions [see Ezer and Mellor, 1992, 1994].

The surface wind stress for each pentad is derived from the Comprehensive Ocean-Atmosphere Data Set (COADS) analyzed by Da Silva et al. [1994]; they are called here the pentad winds. In some experiments the 1945 to 1989 averaged COADS winds are used; they are called here the climatological winds. The pentad wind forcing is very similar to that used by Greatbatch et al. [1991] who claim that the contribution due to changes in the wind are negligible, whereas most of the calculated change in transport between the two pentads is due to the change in the density field that consequently affected the circulation through the joint cffect of baroclinicity and bottom relief (JEBAR), in troduced by Sarkisyan and Ivanov [1971]. We will test this claim by comparing simulations with climatological winds to simulations with pentad winds. The climatological temperature and salinity data of each pentad are the same as those analyzed by Levitus [1989a,b,c].

The methodology of using a numerical model to infer dynamic fields from hydrographic and wind data is as follows: First, the average temperature and salinity of each pentad are interpolated into the model grid, then the model is run for 30 days in a diagnostic mode (holding the density field unchanged) to produce velocity and sea surface height field; finally, a 30-day prognostic calculation allows the density field to adjust to wind and bottom topography. The detailed analysis of the adjustment process, presented by Ezer and Mellor [1994], shows that in middle latitudes the timescale of the fast adjustment is 5 to 10 days. Slow adjustment processes, associated with baroclinic Rossby waves with much longer timescales of months and years also exist but have little effect on the total stream function, surface elevation, and thermohaline circulation during the first year after the diagnostic-prognostic calculations. The simulations are short enough so that the large-scale ocean circulation is still strongly constrained by the hydrographic data. This procedure may be contrasted with that of Sarmiento and Bryan [1982], where long runs were made while relaxing the thermodynamic fields back to climatology.

The spatial changes in temperature and salinity between the two periods have been discussed in detail by Levitus $[1989 a, b, c]$. Figure 1 shows the difference in the area
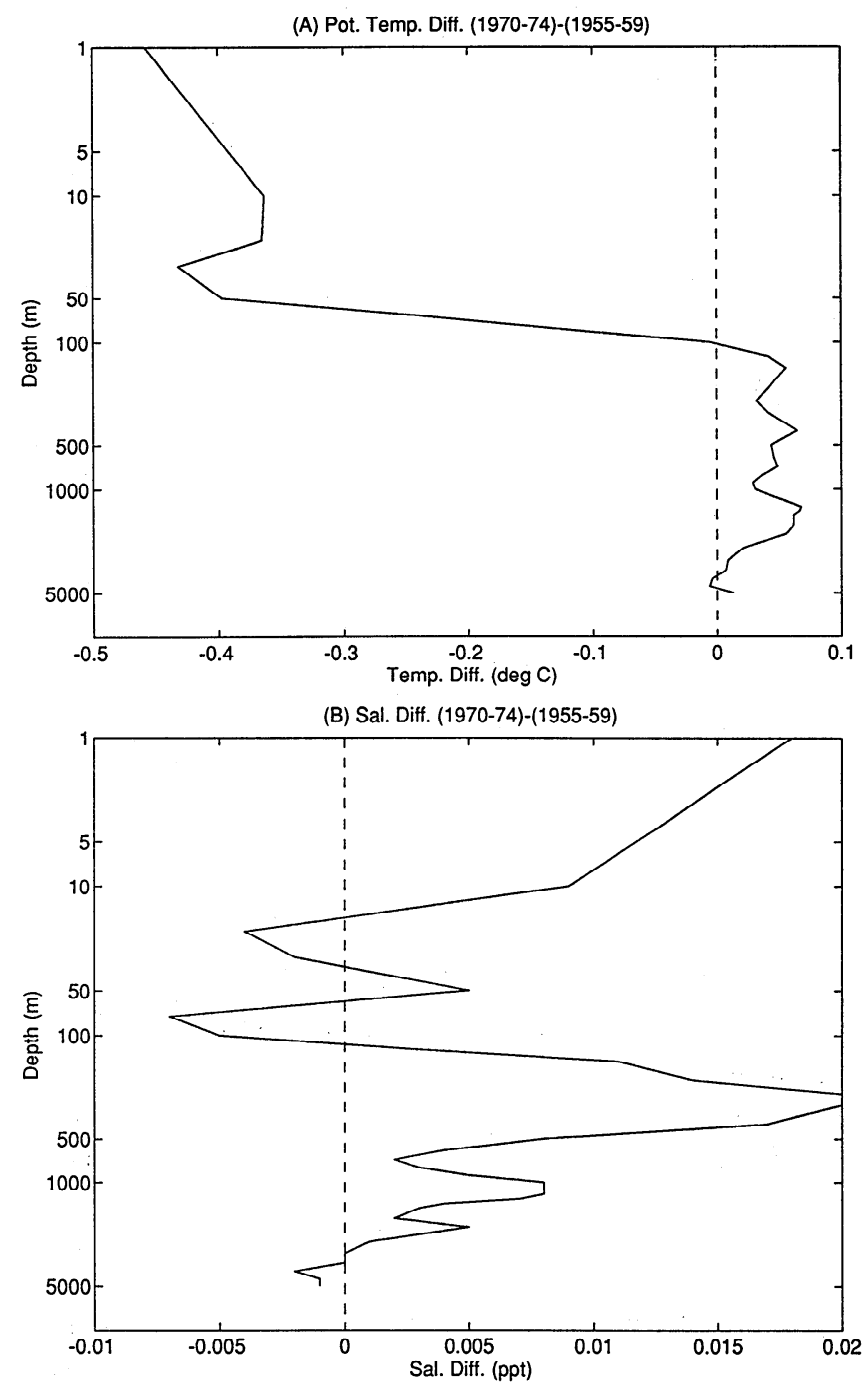

Figure 1. The area averaged (over the model domain) difference in (a) potential temperature, and (b) salinity, between the climatologies of 1970-1974 and 1955-1959 as a function of depth (a logarithmic scale is used to detail the upper ocean). The pentad climatologies are derived from the Levitus [1989a,b,c] analyses. 
averaged values over the model do main, between $10^{\circ} \mathrm{N}$ and $65^{\circ} \mathrm{N}$, of potential temperature and salinity, as calculated from the Levitus pentad data. Over this domain from the 1950s to the 1970 s the potential temperature decreased in the upper $100 \mathrm{~m}$ of the ocean by less than half a degree and increased by less than one-tenth of a degree below $100 \mathrm{~m}$ (Figure 1a); salinity generally increased in most of the water column, except for a decrease in salinity in the deep ocean below 3500 $\mathrm{m}$ and a decrease in salinity in the upper ocean around $20 \mathrm{~m}$ and $75 \mathrm{~m}$ depths. The latter freshening in the upper ocean may be related to the great salinity anomaly [Dickson et al., 1988] which affected the subarctic gyre during the 1970s [see also Levitus, 1989b].

The difference in the COADS wind stresses between the two pentads are shown in Figure 2. When the period with colder sea surface temperature (SST) in the 1970s is subtracted from the period with warmer SST in the 1950s, a cyclonic circulation centered around $30^{\circ} \mathrm{W}$ and $45^{\circ} \mathrm{N}$ is seen. A change in atmospheric conditions as revealed in the study of Kushnir [1994] is consistent with this warm SST anomaly.

\section{Changes in the Horizontal Circulation}

The surface elevation and the total stream function after 60 days and the differences between the two periods are shown in Figures 3 and 4 . Attributed to the Boussinesq approximation, the contribution to the sea level change from the thermal expansion of the water column is neglected in the calculations and thus a correction to the calculated sea level is applied as explained below (see Greatbatch [1994]; G. L. Mellor and T. Ezer, A non-Boussinesq numerical ocean model, submitted to Journal of Geophysical Research, 1994, for more discussion of this effect in ocean models.) The pentad Levitus data show that the mean temperature over the North Atlantic model domain increased by about $0.02^{\circ} \mathrm{C}$ between $1955-1959$ and

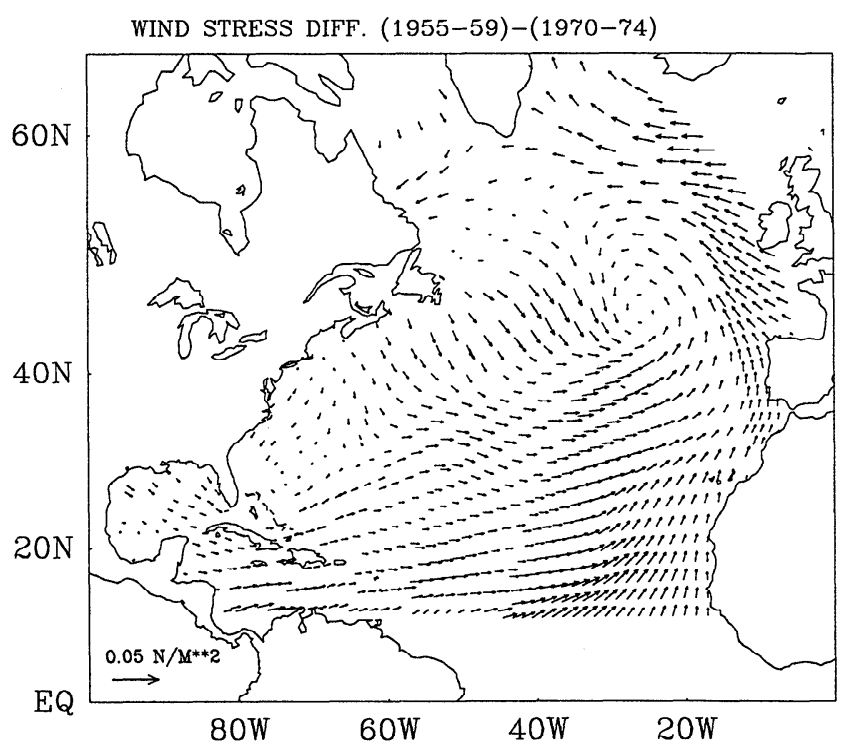

Figure 2. The difference in COADS wind stress (in $\mathrm{N} \mathrm{m}^{-2}$ ) between 1955-1959 and 1970-1974. A scale vector is indicated at the left bottom corner. Vectors are plotted only on model points separated by about $100 \mathrm{~km}$ from each other (at about every fourth point in the southwestern portion of the domain and at almost every grid point in the northeastern portion of the domain).
1970-1974. During this time the warming of the global ocean was only about $0.006^{\circ} \mathrm{C}$. The dynamic adjustment of the North Atlantic due to the fact that it warmed up more than the global ocean is missing since volume is conserved within the model domain due to the Boussinesq approximation and the fact that the net inflow/outflow through the open boundaries is null. However, G. L. Mellor and T. Ezer (submitted manuscript, 1994) have shown that in regional models, a uniform thermal expansion correction based on the change in the volume averaged density is a good estimate for most of the non-Boussinesq effects that are missing from the model (an extension to regional models of a similar correction suggested by Greatbatch [1994] for global models). Therefore we estimate the sea level rise due to thermal expansion between the two periods (about $2 \mathrm{~cm}$ ) from the change in the volume averaged tempcrature over the model domain and applied this correction to the calculated sea level for 19701974.

The surface elevations (Figure 3) show the weakening of the Gulf Stream during the 1970 s as suggested by Levitus [1990], where for example, at $50^{\circ} \mathrm{W}$ the average sea surface height across the Gulf Stream is reduced from about $0.9 \mathrm{~m}$ during the 1950s (Figure 3a) to about $0.7 \mathrm{~m}$ during the $1970 \mathrm{~s}$ (Figure 3b). Between the two pentads, sea level in the subtropical gyre dropped by as much as $20 \mathrm{~cm}$ (compared to the value of $17.5 \mathrm{~cm}$ estimated by the steric sea level calculations of Levitus [1990], while sea level increased by about $18 \mathrm{~cm}$ north of the Gulf Stream (Figure 3c). Note that the change in sea level in the recirculation gyre north of the Gulf Stream is about twice as large as that calculated by Levitus [1990] which may indicate that the velocities at 1500 $m$ (the depth used by Levitus as the reference depth in his steric sea level calculation) are an important part of the computed circulation change between the pentads in this region. Except for the drop in sea level in the subtropical gyre, most of the other regions show an increase in sea level. Later in section 5 , the modeled coastal sea level will be discussed in more detail and compared with observations.

The changes in stream function (Figure 4) show very similar patterns to those calculated by Greatbatch et al. [1991]. The flow in the subtropical gyre and in the Gulf Stream northern recirculation gyre weaken during the 1970 s so that the Gulf Stream was more intense during the 1950 s by about $30 \mathrm{~Sv}$ than it was during the 1970 s. This dramatic weakening of the subtropical gyre as seen by the change in the horizontal transport is the result of changes in the bottom pressure torque associated with the bottom topography of the western side of the Mid-Atlantic Ridge [Greatbatch et al., 1991]. As indicated by Greatbatch et al. [1991], about half of the change in transport is due to changes in the density field below $1500 \mathrm{~m}$, where the number of obscrvations used in the Levitus analysis are limited. Therefore there is still some doubt if those changes are real (the comparisons with other independent data, the observed sea levels, in section 5 will provide further test for those changes). As indicated by Ezer and Mellor [1994], the simple diagnostic model used by Mellor et al. [1982] and Greatbatch et al. [1991] produces similar, vertically averaged circulation to that obtained with the full nonlinear, three-dimensional model, despite the different equations and assumptions used in the two models. Both models produce, for example, the observed northern recirculation gyre off the coast of Nova Scotia [Hogg et al., 1986], while other diagnostic models [e.g., Holland and Hirschman, 1972; Sarmiento and 
(A) SURF. EL. (1955-59)

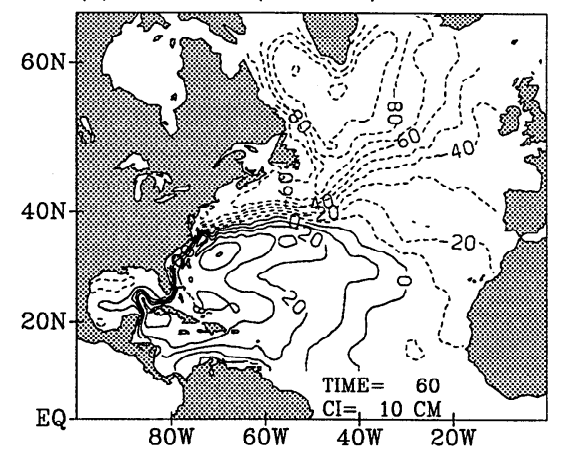

(B) SURF. EL. (1970-74)

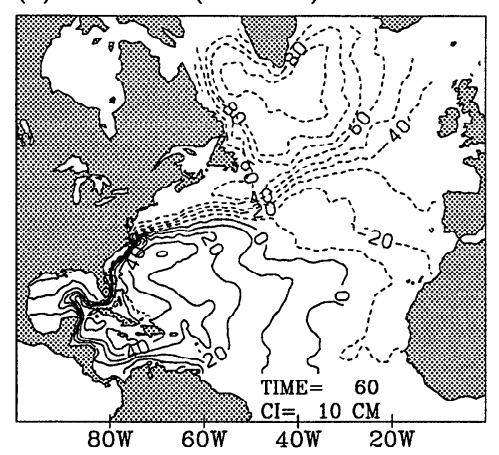

(C) SURF. EL. DIFF. (70-74)-(55-59)

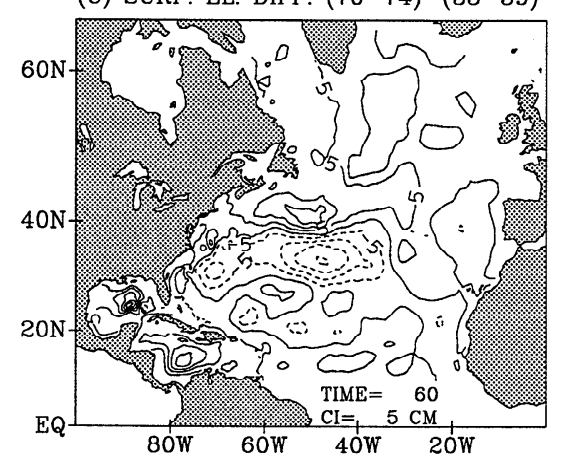

Figure 3. Surface elevation after 60 days for (a) model initialized with the 1955-1959 climatology and (b) model initialized with the 1970-1974 climatology. The difference between (b) and (a) is shown in (c). The contour interval is $10 \mathrm{~cm}$ in (a) and (b) and $5 \mathrm{~cm}$ in (c).

(A) ST. FUNC. (1955-59)

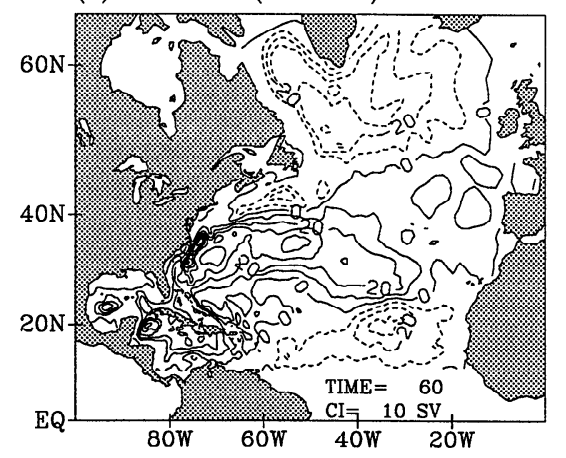

(B) ST. FUNC. (1970-74)

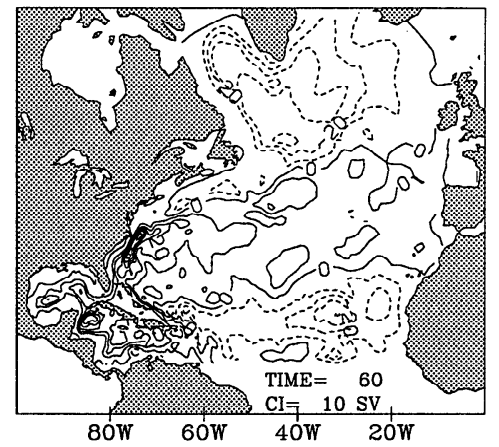

(C) ST. FUNC. DIFF. (70-74)-(55-59)

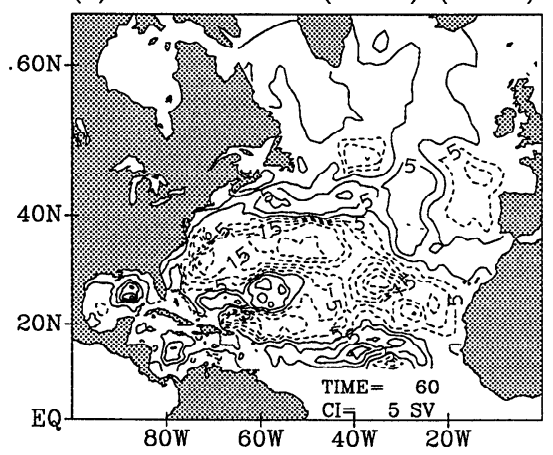

Figure 4. Same as Figure 3 but for total stream function. The contour interval is $10 \mathrm{~Sv}\left(1 \mathrm{~Sv}=10^{6} \mathrm{~m}^{3} \mathrm{~s}^{-1}\right)$ in (a) and (b) and $5 \mathrm{~Sv}$ in (c). 

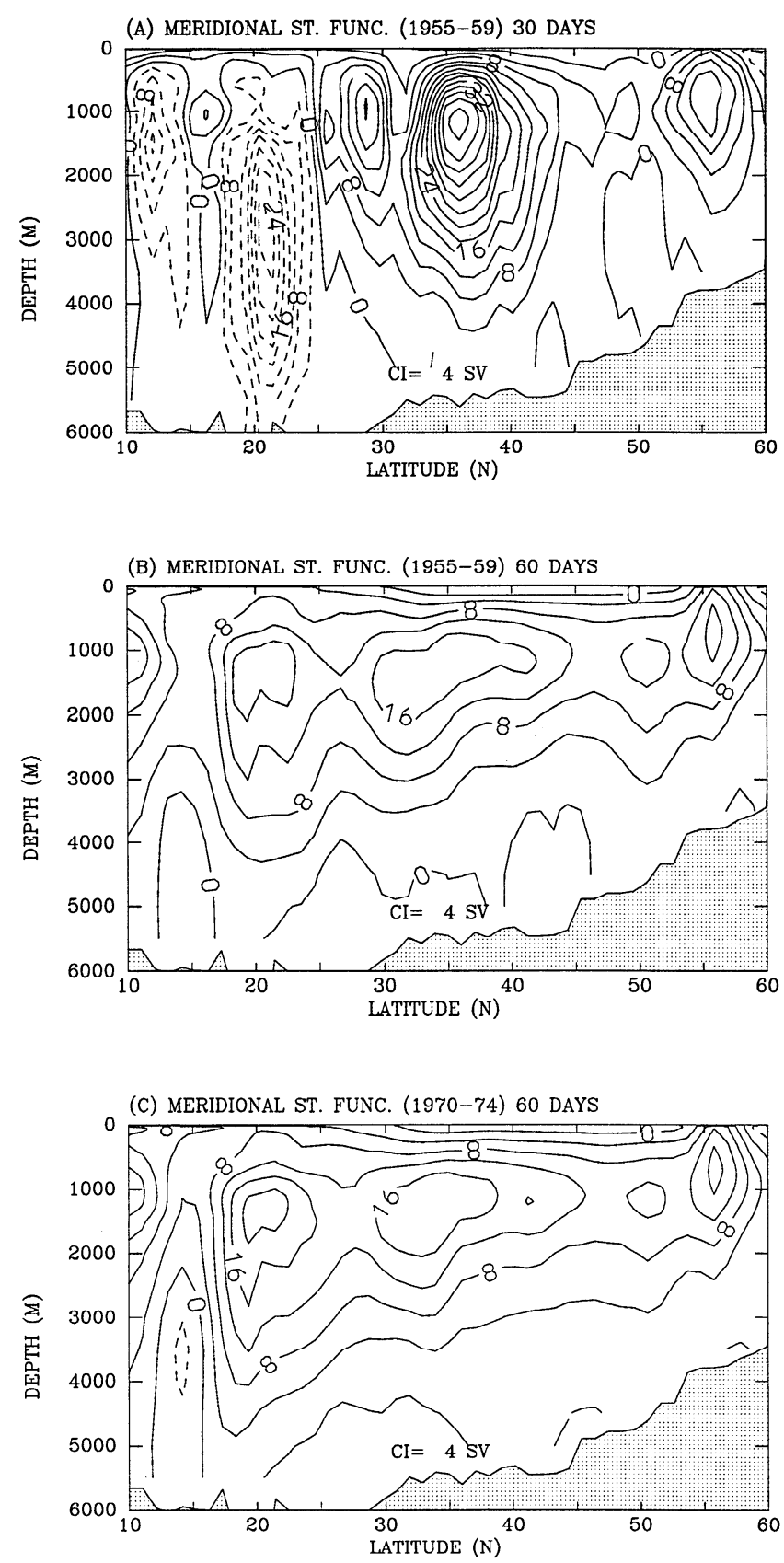

Figure 5. (a) Meridional (zonally averaged) stream function after 30 days of diagnostic calculation for the 1955-1959 period, (b) after additional 30 days of prognostic calculation, and (c) as (b) but for the 1970-1974 period. Contour interval is $4 \mathrm{~Sv}$; dash lines represent negative values.

Bryan, 1982] do not. This gyre north of the Gulf Stream plays a crucial role in maintaining Gulf Stream separation at Cape Hatteras in numerical models [Ezer and Mellor, 1992; Ezer, 1994]. We note here that simulations using climatological mean winds (not shown) instead of the pentad winds show little effect on the horizontal transport in agreement with Greatbatch et al. [1991]. While the results of Figure 4 are not new and are similar to previous estimates using the simpler vertically integrated diagnostic model, they indicate that the interpentadal changes are independent of the specific method used.

\section{Changes in Meridional Circulation and Poleward Heat Transport}

The meridional circulation for 1955-1959 derived from the 30-day, purely diagnostic calculation is noisy and unrealistic (Figure 5a); a diagnostic calculation for 1970-1974 (not shown) is similarly unrealistic. However, after 60 days, when the density and velocity fields are adjusted during the prognostic calculations, the meridional circulation, displayed in Figures $5 \mathrm{~b}$ and $5 \mathrm{c}$, is more realistic. Although the structure of the meridional circulation during the two pentads is quite similar, there are some differences, especially in middle and low latitudes. In the subtropical region, a larger portion of the southward flowing North Atlantic Deep Water (NADW) seems to upwell during the 1970 s south of $20^{\circ} \mathrm{N}$. This change in meridional circulation could relate to the weakening of the southward deep flow associated with the weakening of the subtropical gyre (Figure 4).

The meridional poleward heat flux for the two cases is shown in Figure 6, together with the heat transport estimated by Isemer et al. [1989] (heavy line). At middle latitudes the model gives heat transport values of up to 1.2 petawatts (PW), compared to a value of $1.2 \mathrm{PW}$ calculated by Hall and Bryden [1982] from direct measurements at $24^{\circ} \mathrm{N}$. Note that numerical ocean models [e.g., Beckmann et al., 1994] and inverse optimization calculations [e.g., Tziperman et al., 1992; Marotzke and Wunsch, 1993] often underestimate the maximum poleward heat flux. The difference in the meridional heat flux between the two pentads is shown in Figure 7, which also shows results from calculations using climatological winds instead of pentad winds. It is quite puzzling why the weakening of the Gulf Stream during the 1970s (Figure 4) did not result in a weakening of the poleward heat transport; in fact, in middle latitudes, heat transport usually increased during the 1970s. A possible explanation is that the southward flow of the cold slope water, on the edge of the Gulf Stream northern recirculation gyre, has also weakened during the 1970s; the deep portion of this southward flow is the deep western boundary current that crosses under the Gulf Stream, transporting cold water from high to low latitudes and increasing poleward heat flux. Moreover, during the 1970s the warm

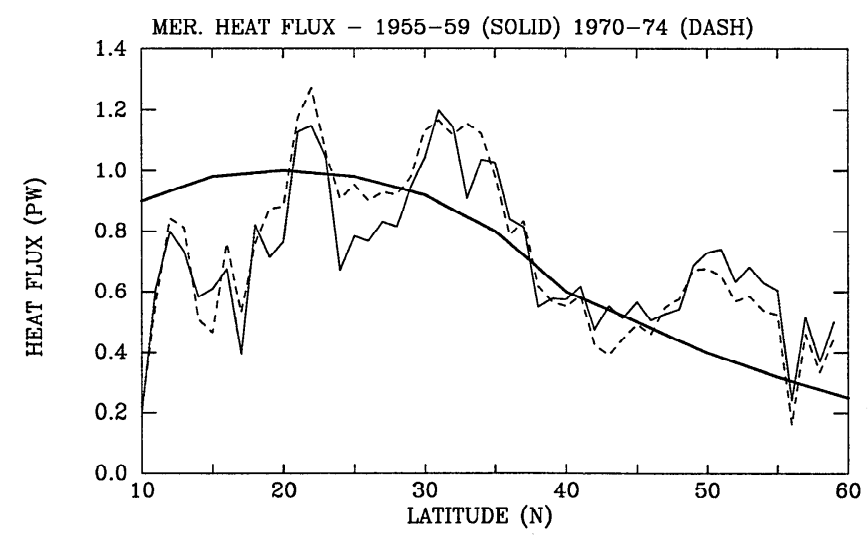

Figure 6. Poleward meridional heat transport (in Petawatts, 1 $\mathrm{PW}=10^{15} \mathrm{~W}$ ) as a function of latitude after 60 days. The solid thin line represents the model calculation for 1955-1959, the dashed thin line represents the model calculation for 19701974, and the solid heavy line represents the estimates of Isemer et al. [1989]. 


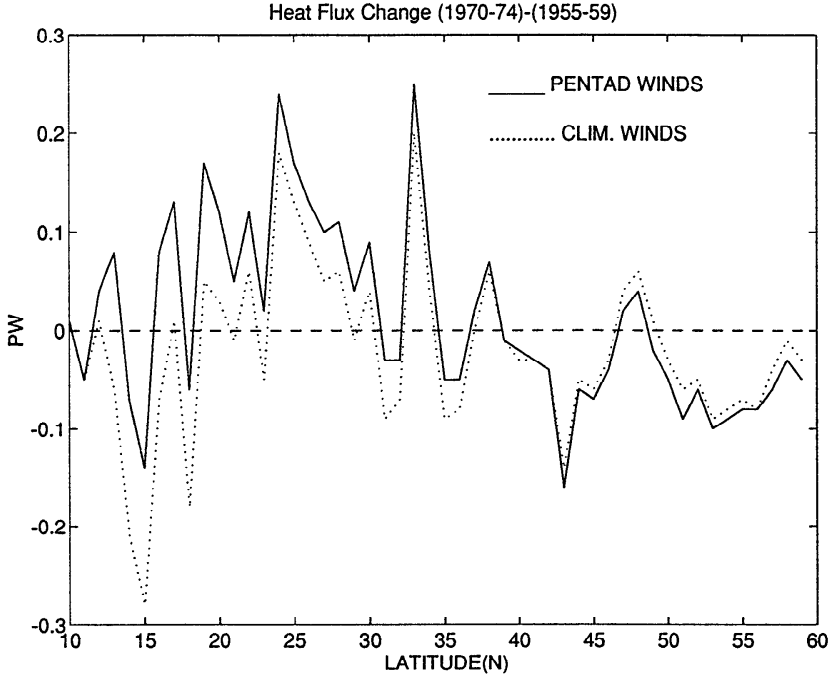

Figure 7. Changes in meridional heat flux (1970-1974 and 1955-1959) as a function of latitude after 60 days. Solid line is from simulations where the winds from each pentad are used (i.e., calculated from Figure 6b); dashed line is from simulations where the same climatological mean wind is used for both pentads.

subtropical waters that entrained into the northward flow east of the Bahamas come from lower latitudes with warmer surface temperatures than those entrained during the $1950 \mathrm{~s}$ (Figure 4), increasing the poleward heat transport during the 1970s. The effect of the atmospheric forcing is evi dent when the pentad winds case is compared with the climatological wind case. This comparison shows that north of $40^{\circ} \mathrm{N}$ the change in winds seems to increase poleward heat flux change, while south of $40^{\circ} \mathrm{N}$ the change in winds seems to decrease poleward heat flux change. The above result can be explained as follows. During the 1950s when surface temperatures were warmer, the wind pattern had a greater cyclonic circulation [Kushnir, 1994, Figure 2], thus decreasing the mean wind stress over the North Atlantic and consequently, decreasing the Ekman contribution to the poleward heat transport; this effect is more pronounced in middle and lower latitudes.

Greatbatch and $X u$ [1993] used a vertical section model at $54^{\circ} \mathrm{N}$ to calculate a poleward heat transport of $0.7 \mathrm{PW}$ for the 1955-1959 pentad and 0.5 PW for 1970-1974 pentad. This compares with a poleward heat transport of $0.63 \mathrm{PW}$ and 0.54 $\mathrm{PW}$ in Figure 6 for $54^{\circ} \mathrm{N}$, respectively. At $24^{\circ} \mathrm{N}$, Greatbatch and $X u$ [1993] computed heat transports of 1.0 and $0.8 \mathrm{PW}$ for 1955-1959 and 1970-1974, respectively. This time the change between the pentads has the opposite sign to that shown for this latitude in Figure 7. There are many possible reasons for this. One may be the fact that the Greatbatch and Xu [1993] calculations are purely diagnostic. Ezer and Mellor [1994] have shown that heat fluxes obtaincd from purcly diagnostic calculations are very noisy, especially in middle latitudes. (However, Greatbatch and Xu [1993] used a two-dimensional section model, rather than the fully three-dimensional model used here, and so avoid difficulties with the JEBAR term in setting the vertically integrated transport). The other may be their treatment of the Florida Straits, where they assumed that the transport there was $29.5 \mathrm{~Sv}$ in both pentads. In the threedimensional model presented here, which includes also the Gulf of Mexico, the calculated Florida Straits transport was 21
Sv for 1955-1959 and 23 Sv for 1970-1974. Because of the nonlinear nature of the calculation of heat transport the different transports in the two models could contribute to the above discrepancy.

\section{Coastal Sea Level}

The model used here is a coastal ocean model as well as a general circulation ocean model, extending from the deep ocean to $10 \mathrm{~m}$ depth on the continental shelf. Therefore it provides a dynamic connection between the general circulation of the deep ocean and variations in coastal sea level. Here we see if the changes in the circulation of the deep ocean produce changes in coastal sea level, and if changes occur, compare them to observed changes.

The coastal sea level in the model is defined as the surface elevation in the grid points closest to the coastal boundary. Figure 8 shows the coastal sea level after 60 days along the North America coast for the two pentads. The calculations have been corrected for the thermal expansion effect by adding $2 \mathrm{~cm}$ to all sea level values of 1970-1974, as discussed beforc. The $80-\mathrm{cm}$ drop in sea level along the western continental boundary of the North Atlantic is in good agreement with Sturges [1974] estimates, but the model provides more spatial details that correlate with changes in the coastline. The result suggests a coastal sea level rise of $5-10 \mathrm{~cm}$ along the North America coasts from the earlier to the later pentad.

To test if the simulated sea level change is real and if changes in winds may play a role, we compare the model results with tide gage data at 15 locations, two stations in the Gulf of Mexico, one station at Bermuda, and 12 stations along

COASTAL SEA LEVEL

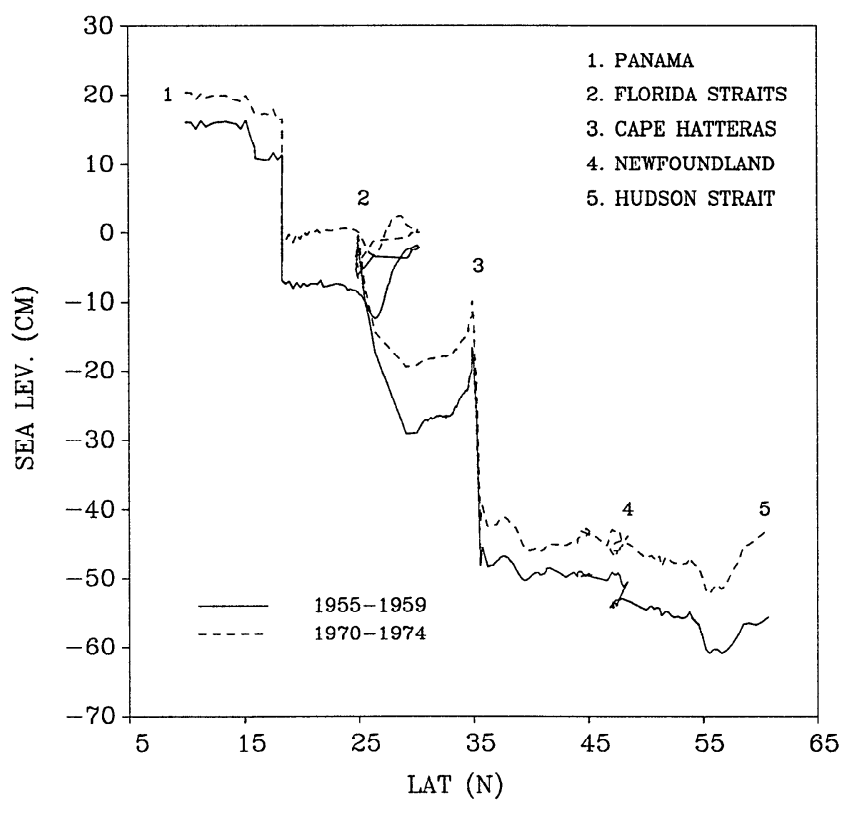

Figure 8. Coastal sea level along the North American continent obtained from the prognostic calculations after 60 days; solid line is for 1955-1959, dashed line is for 1970-1974. The calculation for the 1970s has been corrected for the effect of thermal expansion, where $2 \mathrm{~cm}$ have been added to all values. Numbers from 1 to 5 indicate five selected locations along the coast. 
SEA LEVEL CHANGE (1970-74)-(1955-59)

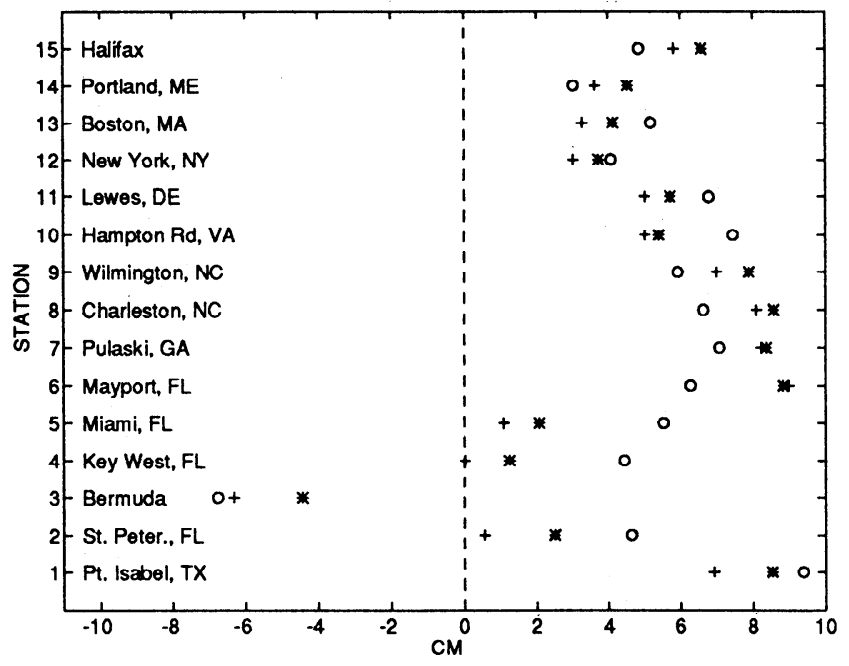

Figure 9. The sea level change between 1955-1959 and 1970-1974 at sea level stations. Observations are indicated by open circles, model predictions are indicated by asterisk and plus signs for runs with pentad winds and with climatological winds, respectively. The tide station locations are indicated on the left.

the United States and Canadian east coasts from Key West, Florida, to Halifax, Nova Scotia (Figure 9). (In the eastern Atlantic and in the northern portion of the domain, model resolution may be inadequate for comparison with data). The observed sea level at those stations were obtained from the National Oceanic and Atmospheric Administration's (NOAA) tide gages, and corrected for the effects of postglacial rebound [Douglas, 1991]. The interpentadal sea level change is the 1970-1974 average minus the 1955-1959 average. Shown are model calculations with pentad winds and with climatological winds. The comparison between model and observed sea level change is relatively good in most stations. Generally, model calculations are closer to observations when pentad winds are used, compared to calculations using climatological winds (a clear exception is at Bermuda, the only noncoastal station, and where sea level drops). For example, the difference between the calculated sea level rise at the coastal stations and the observed sea level rise is on average only $1.7 \mathrm{~cm}$ for the case with pentad winds, compared to an average difference of $2.2 \mathrm{~cm}$ for the case with climatological winds; although this difference may not be statistically significant, it nevertheless does indicate that taking into account long-term changes in the wind pattern may improve the simulated sea level changes. Note also how well the model simulates the local effect of the coastline on sea level rise, as seen in neighboring stations; for example, the change between Port Isabel, Texas, and St. Petersburg, Florida (in the Gulf of Mexico), the change between Key West and Miami, Florida, and between New York and Boston. It implies a complicated small-scale sea level response to changes in circulation and winds. However, at some stations (for example, between Miami and Mayport) there are obvious errors in the model calculations. The latter can be attributed to the model deficiency in resolving the transport through the Florida Straits which is weaker than the observed transport.

\section{Discussion and Conclusions}

This study follows the study of Ezer and Mellor [1994] who presented an effective way to derive the thermohaline circulation of the ocean from observed hydrography and wind data, using diagnostic and short-term prognostic calculations. In this study the method is applied to a climate change problem. In particular, the interpentadal changes in thermohaline structure of the North Atlantic between 1955 1959 and 1970-1974 [Levitus, 1989a,b,c] and their consequences on sea level [Levitus, 1990] and circulation [Greatbatch et al., 1991] are verified. The results from the nonlinear, three-dimensional model extend the steric sea level calculations of Levitus by removing the need to assume a level of no motion. In fact, while they show generally similar sea level changes to those obtained by Levitus, they also indicate that in the recirculation gyre north of the Gulf Stream, much larger changes are obtained now, compared to those obtained from steric calculations. The weakening of the Gulf Stream during the 1970 s by as much as $30 \mathrm{~Sv}$ (obtained here) is comparable to the change obtained by the simple diagnostic model used by [Greatbatch et al., 1991]. Therefore our calculations confirm that the dynamic changes are consistent with changes in the hydrographic data and are independent of methodology.

With the present methodology we were able to evaluate the changes in meridional circulation and in poleward heat transport; such changes could have important implications for processes affecting long-term climatic changes [Delworth et al., 1993; Kushnir, 1994]. Although model results can not be directly verified, they suggest that during the 1970s, thermohaline circulation and poleward heat transport have increased in middle latitudes but decreased in high and low latitudes. It seems that changes of winds do play a role in the changes at middle latitudes through a feedback effect, where colder SST during the 1970 s produces a wind anomaly which increases the wind stress curl [Kushnir, 1994] and consequently, increases the Ekman contribution to the poleward heat transport.

Although Levitus [1990] has shown that the interpentadal changes in steric sea level are generally consistent with observations, we have much more detailed comparison between model calculations and data from 15 sea level stations. The results show good agreement with ob served sea level rise in most cases. The contribution to the sea level rise during the 15-year period between the two pentads from changes in the ocean circulation is larger by a factor of 2 to 4 than the contribution due to the estimated thermal expansion of the water column. The comparison with observations provides also some verification of the negative feedback effect of the wind as discussed before; when changes in wind pattern are taken into account, better agreement with observations is seen in most locations. The availability of long-term satellite altimetry data will provide further data to verify changes in the sea level in the future.

The study suggests that hydrographic data can provide useful information for the detection of climatic changes, where models can be used to infer changes that are not directly measured (e.g., thermohaline circulation and meridional heat flux). The coastal ocean model also provides the dynamic connection between the thermohaline and winddriven circulation of the deep ocean and coastal processes. 
Acknowledgments. We thank A. Goulding for providing us with the pentads data, A. Da Silva for providing us with the latest wind stress analyses, and W. Sturges for providing us with the NOAA sea level data through the FSU Sea Level Center. The research was supported by the NOAA's Atlantic Climate Change Program, grant NA36GP0262, the Office for Naval Research (the Navy Ocean Modeling and Prediction Program) grant N00014-93-1-0037, by NOAA's Coastal Ocean Program, and by the NOAA's Geophysical Fluid Dynamics Laboratory.

\section{References}

Beckmann, A., C. W. Boning, C. Koberle, and J. Willebrand, Effects of increased horizontal resolution in a simulation of the North Atlantic ocean, J. Phys. Oceanogr., 24, 326-344, 1994.

Blumberg, A. F. and G. L. Mellor, A description of a threedimensional coastal ocean circulation model. Three-Dimensional Coastal Ocean Models, Coastal Estuarine Stud., vol. 4, edited by N. S. Heaps, 208 pp., AGU, Washington, D. C., 1987.

Da Silva, A. M., C. C. Young, and S. Levitus, Atlas of surface marine data 1994, vol. 3: Anomalies of heat and momentum fluxes, NOAA Atlas Ser., NESDIS 7, Natl. Oceanic Atmos. Admin., Washington, D. C., In Press, 1995.

Delworth, T., S. Manabe, and R. J. Stouffer, Interdecadal variations of the thermohaline circulation in a coupled ocean-atmosphere model, J. Clim., 6, 1993-2011, 1993.

Dickson, R. R., J. Meinke, S.-A. Malmberg, and A. J. Lee, The great salinity anomaly in the northern North Atlantic, 1968-1982, Prog. Oceanogr., 20, 103-151, 1988.

Douglas, B. C., Global sea level rise, J. Geophys. Res., 96, 6981-6992, 1991.

Ezer, T., On the interaction between the Gulf Stream and the New England seamount chain, J. Phys. Oceanogr., 24, 191-204, 1994.

Ezer, T., and G. L. Mellor, A numerical study of the variability and the separation of the Gulf Stream induced by surface atmospheric forcing and lateral boundary flows, J. Phys. Oceanogr., 22, 660-682, 1992

Ezer, T., and G. L. Mellor, Diagnostic and prognostic calculations of the North Atlantic circulation and sea level using a sigma coordinate ocean model, J. Geophys. Res., 99, 14,159-14,171, 1994.

Greatbatch, R. J., A note on the representation of steric sea level in models that conserve volume rather than mass, J. Geophys. Res., 99, 12,767-12,771, 1994.

Greatbatch, R. J., and J. Xu, On the transport of volume and heat through sections across the North Atlantic: Climatology and the Pentads 1955-1959, 1970-1974, J. Geophys. Res., 98, 10,125-10,143, 1993.

Greatbatch, R. J., A. F. Fanning, A. D. Goulding, and S. Levitus, A diagnosis of interpentadal circulation changes in the North Atlantic, J. Geophys. Res., 96, 22,009-22,023, 1991.

Hall, M. M., and H. L. Bryden, Direct estimates and mechanisms of ocean heat transport, Deep Sea Res., Part A, 29, 339-359, 1982.

Hogg, N. G., R. S. Pickart, R. M. Hendry, and W. J. Smethie, The northern recirculation gyre of the Gulf Stream, Deep Sea Res., Part A, 33, 1139-1165, 1986.

Holland, W. R., and A. Hirschman, A numerical calculation of the circulation in the North Atlantic Ocean, J.Phys. Oceanogr., 2, 336 $354,1972$.
Isayev, G., and $\mathbf{S}$. Levitus, The North Atlantic absolute circulation: Climatology and change between 1950s and 1970s, University of Maryland Report, Univ. Maryland, Takoma Park, Md, 1993.

Isayev, G., and S. Levitus, A diagnosis of the North Atlantic horizontal and vertical circulation with error estimates, J. Geophys. Res., in press, 1995.

Isemer, H. J., J. Willebrand, and L. Hasse, Fine adjustment of large scale air-sea energy flux parameterization by a direct estimate of ocean heat transport, J. Clim., 2, 1173-1184, 1989.

Kushnir, Y., Interdecadal variations in North Atlantic sea surface temperature and associated atmospheric conditions, J. Clim., 7, 142 $157,1994$.

Levitus, S., Climatological atlas of the world ocean, NOAA Prof. Pap., 13, 173 pp., Natl. Oceanic and Atmos. Admin., Washington, D. C., 1982.

Levitus, S., Interpentadal variability of temperature and salinity at in termediate depths of the North Atlantic Ocean, 1970-1974 versus 1955-1959, J. Geophys. Res., 94(C5), 6091-6131, 1989a.

Levitus, S., Interpentadal variability of salinity in the upper $150 \mathrm{~m}$ of the North Atlantic Ocean, 1970-1974 versus 1955-1959, J. Geophys. Res., 94(C7), 9679-9685, 1989b.

Levitus, S., Interpentadal variability of temperature and salinity in the deep North Atlantic, 1970-1974 versus 1955-1959, J. Geophys. Res., 94(C11), 16,125-16,131, 1989c.

Levitus, S., Interpentadal variability of steric sea level and geopotential thickness of the North Atlantic Ocean, 1970-1974 versus 1955-1959, J. Geophys. Res., 95(C4), 5233-5238, 1990.

Marotzke, J., and C. Wunsch, Finding the steady state of a general circulation model through data assimilation: Application to the North Atlantic Ocean, J. Geophys. Res., 98, 20,149-20,167, 1993.

Mellor, G. L., and T. Yamada, Development of a turbulence closure model for geophysical fluid problems, Rev. Geophys., 20, 851-875, 1982.

Mellor, G. L., C. Mechoso, and E. Keto, A diagnostic calculation of the general circulation of the Atlantic Ocean, Deep Sea Res., Part A, 29, 1171-1192, 1982.

Sarkisyan, A. S., and V. F. Ivanov, Joint effect of baroclinicity and bottom relief as an important factor in the dynamics of sea currents, Izv. Acad. Sci. USSR Atmos. Oceanic Phys., Engl. Transl., no. $7,173-188,1971$

Sarmiento, J. L., and K. Bryan, An ocean transport model for the North Atlantic, J. Geophys. Res., 87, 394-408, 1982.

Sturges, W., Sea level slope along continental boundaries, J. Geophys. Res., 79, 825-830, 1974.

Tziperman, E., W. C. Thacker, R. B. Long, S.-M. Hwang, and S. R. Rintoul, Oceanic data analysis using a general circulation model. Part II: A North Atlantic model, J. Phys. Oceanogr., 22, 1458-1485, 1992.

T. Ezer and G. L. Mellor, Program in Atmospheric and Oceanic Sciences, P.O. Box CN710, Sayre Hall, Princeton University, Princeton, NJ 08544-0710. (e-mail: ezer@splash.princeton.edu; glm@splash.princeton.edu)

R. J. Greatbatch, Department of Physics, Memorial University of New Foundland, St. John's, New Foundland, Canada A1B 3X7.

(Received September 13, 1994; revised February 6, 1995; accepted February 9, 1995.) 